\title{
Remyelination of the Rat Spinal Cord by Transplantation of Identified Bone Marrow Stromal Cells
}

\author{
Yukinori Akiyama, ${ }^{1,2,3}$ Christine Radtke, ${ }^{1,2}$ and Jeffery D. Kocsis ${ }^{1,2}$ \\ ${ }^{1}$ Department of Neurology, Yale University School of Medicine, New Haven, Connecticut 06516, 2Neuroscience Research \\ Center, Veterans Affairs Medical Center, West Haven, Connecticut 06516, and ${ }^{3}$ Department of Neurosurgery, Sapporo \\ Medical University School of Medicine, Sapporo, Hokkaido 060-8543, Japan
}

\begin{abstract}
Bone marrow contains a population of stem-like cells that can differentiate into neurons or glia. Stromal cells from green fluorescent protein (GFP)-expressing mice were isolated by initial separation on a density gradient and then cultured as adherent cells on plastic that proliferated in culture to confluency with a typical flattened elongative morphology. The large majority of the isolated stromal cells were GFP expressing and immunopositive for collagen type I, fibronectin, and CD44. Transplantation of these cells by direct microinjection into the demyelinated spinal cord of the immunosuppressed rat resulted in remyelination. The remyelinated axons showed characteristics of both central and peripheral myelination as observed by electron
\end{abstract}

Bone marrow provides a source of circulating erythrocytes, platelets, monocytes, granulocytes, and lymphocytes, which are derived from a hematopoietic stem cell (Phinney et al., 1999). The marrow stroma is complex tissue that contains cells that are required for lineage commitment of hematopoietic cells. Although initially thought to be primarily hematopoietic support cells, the marrow stromal cells (MSCs) also contain nonhematopoietic cells that can differentiate into a variety of mesenchymal cell types, including bone (Rickard et al., 1994; Pereira et al., 1995), cartilage (Ashton et al., 1980), muscle (Ferrari et al., 1998), and glia and neurons (Azizi et al., 1998; Woodbury et al., 2000). The hypothesis has been generated that MSCs are a unique cell in marrow that differentiate along multiple mesenchymal cell lineages that can differentiate into nonhematopoietic and nonlymphopoietic tissues (Owen, 1988; Caplan, 1991; Prockop, 1997). The stromal cells have a propensity to adhere to tissue culture plastic, and this property has been used as a means to isolate them from bone marrow (Friedenstein, 1976; Wang and Wolf, 1990; Simmons et al., 1991).

Neural stem cells are self-renewing precursors of neurons and glia and can be derived from the adult brain (Reynolds and Weiss, 1992; Lois and Alvarez-Buylla, 1993; Gage et al., 1995; Johe et al., 1996; Johansson et al., 1999), including that of humans (Kukekov et al., 1999; Vescovi et al., 1999; Akiyama et al., 2001). When expanded and injected into demyelinated lesions in the CNS, these cells can form myelin (Brustle et al., 1999; Keirstead

Received Feb. 22, 2002; revised May 9, 2002; accepted May 20, 2002.

This work was supported by National Institutes of Health Grant NS10174, the Department of Veterans Affairs, and National Multiple Sclerosis Society Grant RG2135.

Correspondence should be addressed to Dr. Jeffrey D. Kocsis, Yale University School of Medicine, Neuroscience Research Center (127A), Veterans Affairs Medical Center, West Haven, CT 06516. E-mail: jeffery.kocsis@yale.edu.

Copyright (C) 2002 Society for Neuroscience 0270-6474/02/226623-08\$15.00/0 microscopy; conduction velocity of the axons was improved. GFP-positive cells and myelin profiles were observed in the remyelinated spinal cord region, indicating that the donorisolated stromal cells were responsible for the formation of the new myelin. The GFP-positive cells were colocalized with myelin basic protein-positive and P0-positive cellular elements. These findings indicate that cells contained within the stromal cell fraction of the mononuclear cell layer of bone marrow can form functional myelin during transplantation into demyelinated spinal cord.

Key words: stromal cell; remyelination; cell transplantation; nonhematopoietic stem cells; myelin; mesenchymal stem cells

et al., 1999; Akiyama et al., 2001) and improve conduction velocity (Akiyama et al., 2001). Given the pluripotency of MSCs, the prospect of using them to elicit remyelination has been explored (Chopp et al., 2000; Sasaki et al., 2001).

Indeed, direct injection of cells acutely isolated from the mononuclear cell fraction of adult bone marrow, which contains MSCs, into the demyelinated spinal cord elicits remyelination (Sasaki et al., 2001), as does intravenous delivery of these cells (Akiyama et al., 2002). Systemic injection of bone marrow cells into lethally $\mathrm{X}$-irradiated mice leads to differentiation of neuronal cells in brain (Brazelton et al., 2000; Mezey et al., 2000) and enhances functional recovery in rodents with middle cerebral artery infarction (Chen et al., 2001) and after contusive spinal cord injury (Chopp et al., 2000). Although acutely isolated cells from the mononuclear fraction of bone marrow can remyelinate spinal cord axons (Sasaki et al., 2001), it is important to isolate the cell type within the mononuclear layer that is responsible for the remyelination. This would indicate the possibility of harvesting and expanding a homogeneous population of cells to be used for cell therapy studies. The goal of the present study was to isolate MSCs from green fluorescent protein (GFP)-expressing mice and determine their myelinating potential when transplanted into the demyelinated spinal cord. We observed that isolated and expanded GFP-expressing bone marrow stromal cells injected into the demyelinated rat spinal cord resulted in considerable remyelination with some recovery of axonal function.

\section{MATERIALS AND METHODS}

GFP-expressing mice. GFP expressing mice [C57BL/6-TgN(ACtbEGFP] (The Jackson Laboratory, Bar Harbor, ME) were bred and used for collection of bone marrow cells. GFP-expressing mice were identified by their fluorescence properties, and 8-week-old animals were used for bone marrow cell preparation.

Isolation of mice bone marrow stromal cells. Bone marrow $(10 \mu \mathrm{l})$ was obtained from femurs and tibias of GFP mice using a heparinized 24 
gauge needle. The samples were diluted in $5 \mathrm{ml}$ of neural progenitor cell basal medium (NPBM) (Clonetics, San Diego, CA), which contains $10 \%$ fetal bovine serum (FBS), epidermal growth factor, basic fibroblast growth factor, and neural survival factors (NSF). The composition of the NSF (Clonetics) is proprietary. The bone marrow suspension was loaded on a $5 \mathrm{ml}$ Ficoll solution using a Pasteur pipette. The cells were collected from the mononuclear cell layer after centrifugation $(560 \times g, 25 \mathrm{~min})$ and resuspended in $5 \mathrm{ml}$ of NPBM. After a second centrifugation $(560 \times$ $g, 25 \mathrm{~min})$, the cells were collected in NPBM, were plated on untreated plastic culture dishes, and incubated for $3 \mathrm{~d}$, and the nonadherent cells were removed by replacing the medium. The cells were maintained in culture for 2 weeks and then treated with $0.25 \%$ trypsin and $1 \mathrm{~mm}$ EDTA for $5 \mathrm{~min}$, followed by removal from the flask and replating in new culture dishes.

Animal preparation and transplantation. A focal demyelinated lesion was created in the dorsal funiculi of adult Wistar rats (12 weeks old) of the spinal cord using $\mathrm{X}$-irradiation and ethidium bromide (EB) injections (EB-X) (Blakemore and Crang, 1985, 1989; Honmou et al., 1996). Briefly, rats were anesthetized with ketamine $(75 \mathrm{mg} / \mathrm{kg}$, i.p.) and xylazine (10 $\mathrm{mg} / \mathrm{kg}$, i.p.), and a 40 Grays surface dose of X-irradiation was focally delivered to the spinal cord caudal to the 10th thoracic level (T-10) using a Siemens (Erlangen, Germany) Stabilipan radiotherapy machine (Honmou et al., 1996). Three days after irradiation, rats were anesthetized, and a laminectomy was performed at T-11. The demyelinating lesion was induced by the direct injection of EB into the dorsal column via a drawn glass micropipette. Injections of $0.5 \mu \mathrm{l}$ of $0.3 \mathrm{mg} / \mathrm{ml} \mathrm{EB}$ in saline were made at depths of 0.7 and $0.4 \mathrm{~mm}$ at three longitudinal distances separated by $2 \mathrm{~mm}$ each. A suspension of cultured bone marrow stromal cells $\left(5.0 \times 10^{3}\right.$ cells $\left./ \mu \mathrm{l}\right)$ in $1 \mu \mathrm{l}$ of medium or $1 \mu \mathrm{l}$ of medium without cells for control were injected into the middle of the EB-X-induced lesion $3 \mathrm{~d}$ after EB injection. Both control and cell-transplanted rats were immunosuppressed with cyclosporine $\left(10 \mathrm{mg} \cdot \mathrm{kg}^{-1} \cdot \mathrm{d}^{-1}\right.$, s.c.; Sandoz, Basel, Switzerland) $1 \mathrm{~d}$ before spinal cord injection and each day thereafter.

Field potential recording. Three weeks after transplantation, the rats were deeply anesthetized (60 mg/ $\mathrm{kg}$ sodium pentobarbital), and then spinal cords of normal control $(n=12)$, demyelinated $(n=12)$, and transplanted rats $(n=9)$ were quickly removed and maintained in an in vitro submersion-type recording chamber with a modified Krebs' solution containing the following (in $\mathrm{mM}$ ): $124 \mathrm{NaCl}, 26 \mathrm{NaHCO}_{3}, 3.0 \mathrm{KCl}, 1.3$ $\mathrm{NaH}_{2} \mathrm{PO}_{4}, 2.0 \mathrm{MgCl}_{2}, 10$ dextrose, and $2.0 \mathrm{CaCl}_{2}$ (saturated with $95 \% \mathrm{O}_{2}$ and $5 \% \mathrm{CO}_{2}$ ). Field potential recordings of compound action potentials were obtained at $36^{\circ} \mathrm{C}$ with glass microelectrodes $(1-5 \mathrm{M} \Omega ; 1 \mathrm{M} \mathrm{NaCl}$ ) positioned in the dorsal columns, and signals were amplified with an high-input impedance amplifier. The axons were activated by electrical stimulation of the dorsal columns with bipolar Teflon-coated stainless steel electrodes cut flush and placed lightly on the dorsal surface of the spinal cord. Constant current stimulation pulses were delivered through stimulus isolation units and the timing device. The recorded field potentials were positive-negative-positive waves corresponding to sourcesink-source currents associated with propagating axonal action potentials; the negativity represents inward current associated with the depolarizing phase of the action potential. All variances represent $\pm \mathrm{SE}$. Differences among groups were assessed by unpaired two-tailed $t$ test to identify individual group differences. Differences were deemed statistically significant at $p<0.05$.

Immunocytochemistry. Cultured bone marrow stromal cells were rinsed in PBS and fixed for 15 min with a fixative solution containing $4 \%$ paraformaldehyde in $0.14 \mathrm{M}$ Sorensen's phosphate buffer, $\mathrm{pH} 7.4$, at $4^{\circ} \mathrm{C}$. Fixed cells were incubated for $15 \mathrm{~min}$ in a blocking solution containing $0.2 \%$ Triton X-100 and 5\% normal goat serum (NGS) before incubation with the primary antibody. The primary antibodies used were antifibronectin (1:400, mouse monoclonal; Sigma, St. Louis, MO) and anticollagen type I (1:100, rabbit polyclonal; Chemicon, Temecula, CA). Living cells in culture were immunostained with anti-CD44 antibody (1:100, mouse monoclonal; VMRD, Pullman, WA) and were then incubated with anti-CD44 antibody in NPBM containing 10\% FBS overnight at $37^{\circ} \mathrm{C}$, followed by washing three times with PBS containing with $5 \%$ FBS. The primary antibody was visualized using goat anti-mouse or goat anti-rabbit IgG antibody (1:200; Molecular Probes, Eugene, OR). After immunostaining, coverslips were mounted cell-side down on microscope slides using mounting medium (Dako, High Wycombe, UK). Two controls were run for all immunocytochemical experiments. Tissue was processed without incubation in either primary or secondary antibody. No background fluorescence was observed in either of these controls.
Histological processing. After electrophysiological recordings were obtained, each spinal cord was prepared for histological study. The histological analysis was blinded until completion of the study. The spinal cords were fixed for $24 \mathrm{hr}$ in $4 \%$ paraformaldehyde in $0.14 \mathrm{M}$ Sorensen's phosphate buffer, $\mathrm{pH}$ 7.4. Tissue was washed three times and stored overnight in buffer. The lesions in the spinal cord were separated into rostral and caudal halves. One-half of the tissue from the lesion was separated for cryosections to look for GFP fluorescence and immunohistochemistry, and the other half was prepared for plastic embedding for light and electron microscopic analysis, respectively. For immunohistochemistry, the tissue was placed in $30 \%$ sucrose solution in PBS until the tissue sank. Cryosections were cut, rinsed, and blocked with $10 \%$ NGS and $0.4 \%$ Triton X-100 in Tris-buffered saline (TBS) or PBS for 30 $\mathrm{min}$ at room temperature. Sections were incubated with primary antibodies mouse anti-myelin basic protein (MBP) (1:1000 dilution; Sternberger Monoclonals, Exeter, UK) or mouse anti-P0 (1:1000 dilution; obtained from Dr. Juan J. Archelos, Department of Neurology, University of Graz, Graz, Austria) overnight at $4{ }^{\circ} \mathrm{C}$. MBP was diluted with $2 \%$ NGS and $0.4 \%$ Triton X-100 in TBS, and P0 was diluted with PBS. After washing, the sections were incubated with secondary antibody (Alexa Fluor 594 goat anti-mouse secondary antibody; 1:1000 dilution; Molecular Probes) for $1 \mathrm{hr}$ at room temperature in the dark and mounted with fluorescent mounting medium (Dako). Slides were examined on a Nikon (Tokyo, Japan) Eclipse 800 epifluorescent microscope. For plastic sections, the segments were postfixed with $1 \%$ osmium tetroxide for $4 \mathrm{hr}$, dehydrated in graded ethanol solutions, and embedded in Epox-812 (Ernest Fullam, Latham, NY). The tissue was serially sectioned on an ultramicrotome. Finally, the sections were counterstained with $0.5 \%$ methylene blue $-0.5 \%$ azure II in $0.5 \%$ borax. The sections were examined with a Nikon Eclipse 800 and photographed with a Spot RT Color CCD camera (Diagnostic Instruments, Inc.). Thin plastic sections were counterstained with uranyl and lead salts and examined with a Zeiss (Oberkochen, Germany) EM902A electron microscope operating at $80 \mathrm{kV}$.

\section{RESULTS GFP expression in bone marrow cells from GFP-expressing mice}

Bone marrow was examined from a transgenic mouse line with an enhanced GFP (EGFP) cDNA under the control of chicken $\beta$-actin promoter and cytomegalovirus enhancer (C57BL/6TgN(ACTbEGFP)1Osb; The Jackson Laboratory). This model is suggested to have GFP expression in all tissues, except for erythrocytes and hair (Okabe et al., 1997). We found that in acutely isolated raw bone marrow from this strain that $19.6 \pm$ $4.9 \%$ of cells were GFP positive and that, in the mononuclear layer separated on a density gradient, that $40.9 \pm 9.8 \%$ of cells were GFP positive. In the adherent cell population of the bone marrow, i.e., stromal cells, $62.5 \pm 5.0 \%$ were GFP positive at $7 \mathrm{~d}$ in culture, and, at 14 and $21 \mathrm{~d}$ in culture, $62.4 \pm 12.2$ and $66.78 \pm$ $7.9 \%$, respectively, were positive for GFP. This indicates that a significant proportion of cells in the stromal cell fraction express GFP in this model system. At 2 weeks in culture, the adherent cells increased in number from $0.42 \times 10^{6}$ to $2.1 \times 10^{6}$ cells $/ \mathrm{ml}$, indicating a near fivefold increase in the number of cultured stromal cells.

Figure $1 A$ is a field of living adherent cells in culture obtained at 2 weeks showing a number of GFP-expressing cells. The overlay of the fluorescent image of Figure $1 A$ with a differential interference contrast image (Fig. $1 B$ ) shows that both GFPpositive and -negative cells are present in this field. A variety of cell morphologies was present at this time culture. These included flattened process-bearing cells, fusiform cells, and rounded cells. There was no relationship between GFP expression and cell morphology, i.e., GFP-positive and -negative cells were present across the cell population. Figure $1 C$ is a higher-power field of fixed cells showing a cluster of flattened, process-bearing GFPpositive stromal cells at 2 weeks in culture. Stromal cells isolated 

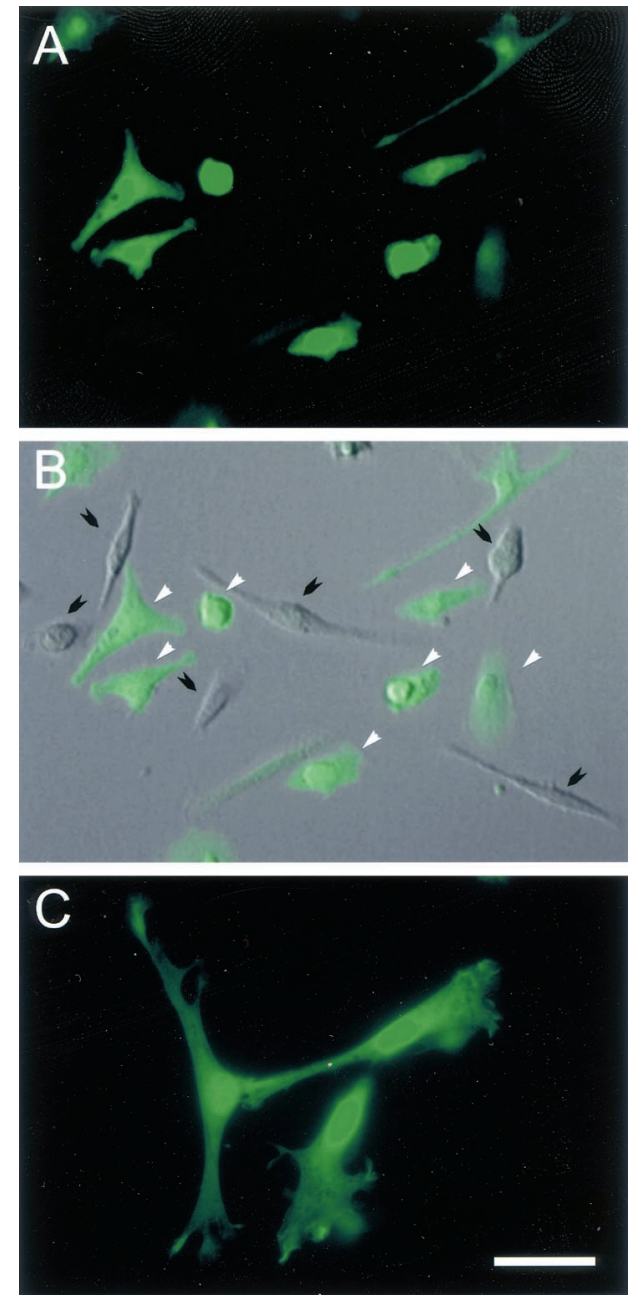

Figure 1. GFP-expressing mouse bone marrow stromal cells cultured for $14 \mathrm{~d}$. $A$, A field of GFP-expressing cells and superimposition on a DIC image of the same field $(B)$. The cells vary in morphology from flattened and fusiform to rounded. White arrows indicate positive and black arrows indicate negative fluorescent cells. A higher-power image $(C)$ shows a collection of GFP-expressing cells, which are flattened and process bearing. Scale bar: $A, B, 50 \mu \mathrm{m} ; C, 30 \mu \mathrm{m}$.

in this manner have been reported to express collagen type I, fibronectin, and CD44 (Zohar et al., 1997; Azizi et al., 1998; Conget and Minguell, 1999; Pittenger et al., 1999). Many of the GFP-expressing cells coexpressed GFP with collagen I (Fig. $2 A$ ), fibronectin (Fig. $2 B$ ), or CD44 (Fig. 2C). The isolation of plastic adherent cells plated from the mononuclear layer of bone marrow and the expression of the above three surface antigens places these cells as conventionally defined marrow stromal cells. Although we did not do triple-labeling experiments for these antigens, the large percentage of cells that coexpressed GFP with each of the antigens studied suggest that collagen I, fibronectin, and CD44 are coexpressed on the stromal cells.

\section{Remyelination after transplantation of bone marrow stromal cells}

In preparation for injection into the demyelinated spinal cord, the stromal cells were grown in culture for 2 weeks, trypsinized, washed, and suspended in NPBM at a cell concentration of $\sim 5.0 \times 10^{3}$ cells $/ \mu$ l. Control injections were with NPBM alone to control for possible effects of the trophic factors and mitogens in
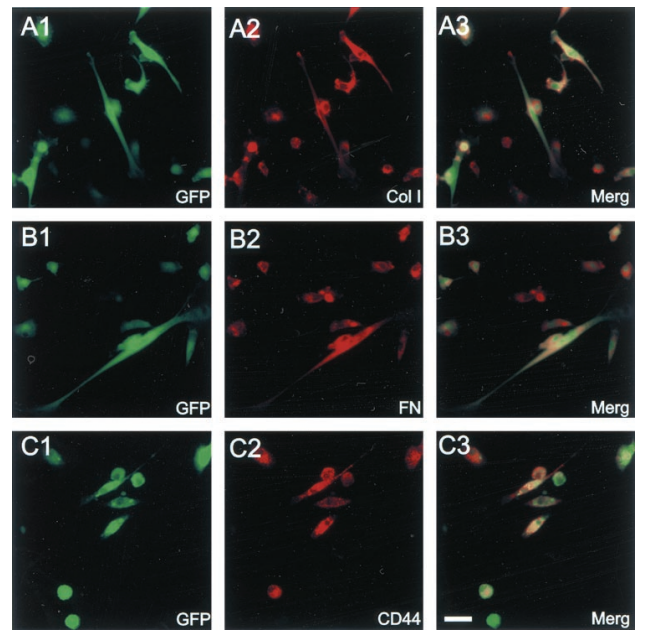

Figure 2. Immunocytochemical characterization of cultured GFPexpressing mouse bone marrow stromal cells. Green fluorescence $(A 1, B 1$, $C 1)$ shows GFP-expressing bone marrow stromal cells from three different cultures (14 d in culture). Red fluorescence $(A 2, B 2, C 2)$ shows immunoreactivity to collagen type I ( $\mathrm{Col} I)$, fibronectin $(F N)$, and $\mathrm{CD} 44$, respectively. $A 3, B 3$, and $C 3$ are coregistered images from their respective panels in 1 and 2. The large majority of GFP fluorescent cells were positive for collagen type I, fibronectin, and CD44. Scale bar, $10 \mu \mathrm{m}$.

the medium. Cells or control medium solution were injected into the center of the lesion (see Materials and Methods), and the immunosuppressed rats were prepared for histology at 3 weeks or for in vitro electrophysiological recording. Figure $3 A 1$ shows a low-power micrograph of a plastic-embedded section from the normal dorsal columns. A higher-power micrograph (Fig. 3A2) from this section shows the abundance of myelinated axons in the normal dorsal funiculus. In the EB-X-lesioned dorsal funiculus (Fig. 3A3), there is virtually no myelin; the field is composed of demyelinated axons, cellular debris, and phagocytic cells. It is important to note that, in this model system, virtually no endogenous repair occurs for up to 6-8 weeks after lesion induction (Blakemore and Crang, 1985, 1989; Honmou et al., 1996). Three weeks after direct microinjection of bone marrow stromal cells into the demyelinated spinal cord, relatively extensive remyelination is observed (Fig. 3B). The low-power micrograph in Figure $3 B 1$ shows the lesion site. The darker stained area in the central region of the dorsal funiculus is replete with remyelination profiles. The boxed areas ( 2 and 3 ) in Figure $3 B 1$ are shown at higher power in Figure 3, B2 and B3, respectively. Notice the near complete remyelination in the center of the lesion $(B 2)$ and the partial remyelination at the lateral margin of the lesion (Fig. 3B3). The lighter stained areas on the lateral margins of the lesion zone showed poor myelination (Fig. 3B1), and the remyelination was most competent in the dorsoventral axis of the dorsal funiculus.

The electron micrographs in Figure 4 show the structure of the remyelinated axons in greater detail. A lower-power field shows both demyelinated and remyelinated axons obtained at the edge of the repair zone (Fig. $4 A$ ). Some of the myelinated profiles are associated with large nuclei characteristic of peripheral myelin (arrows). One can also see cells with large nuclei that have cytoplasmic regions surrounding axons but have not as yet formed myelin (asterisks). A higher magnification of a myelinated axon associated with a large nucleus (Fig. $4 B$ ) indicates that these myelinated axons are surrounded by a basement membrane (arrowheads). These morphologies sug- 
Figure 3. Morphology of control, demyelinated, and remyelinated dorsal funiculus. Normal dorsal funiculus (area outlined by arrowheads in $A 1)$ of the T-11 spinal cord is shown at low $(A 1)$ and high (A2) power. $A 3$, High-power field of demyelinated axons in control lesion with injection of control vehicle without cells. B1, A low-power micrograph of the dorsal funiculus lesion zone 3 weeks after GFP mouse bone marrow stromal cell transplantation. The high-power fields in $B 2$ and $B 3$ were obtained from the boxed areas in $B 1$ marked 2 and 3, respectively. Note that nearly all of the axons in the central lesion zone in B2 are remyelinated, but that demyelinated axons are present at the lateral edge of the lesion (B3). $D F$, Dorsal funiculus; $D H$, dorsal horn. Scale bar: $A 1, B 1,100 \mu \mathrm{m} ; A 2, A 3$, $B 2, B 3,15 \mu \mathrm{m}$. All images were obtained with Nikon Eclipse 800 epifluorescent microscope.
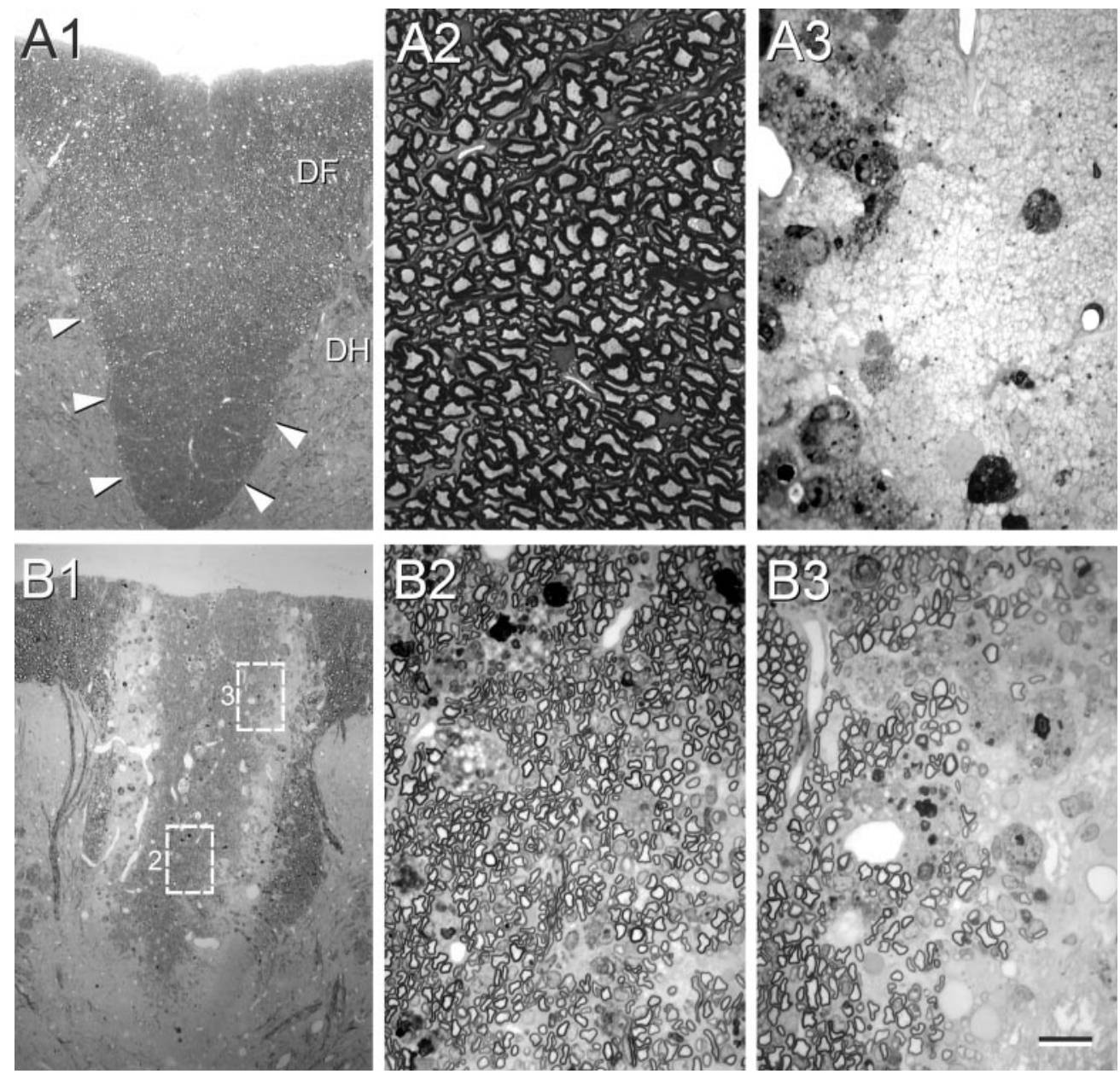

Figure 4. Electron micrographs of remyelinated axons in the dorsal funiculus of the spinal cord after bone marrow stromal cell transplantation. $A$, A field of axons showing some with myelin associated with a large cytoplasmic and nuclear surround, demyelinated axons, and axons surrounded by cytoplasmic regions but not yet forming myelin. Some of the myelinated axons did have the large nuclear and cytoplasmic surrounds and others without. $B$, A higher-power electron micrograph illustrating a remyelinated axon characteristic of a peripheral myelination pattern. Note the large cytoplasmic and nuclear domains and the basement membrane (arrowheads) surrounding the entire axon and cellular complex. Scale bar: $A, 5 \mu \mathrm{m}$; $B, 1 \mu \mathrm{m}$.
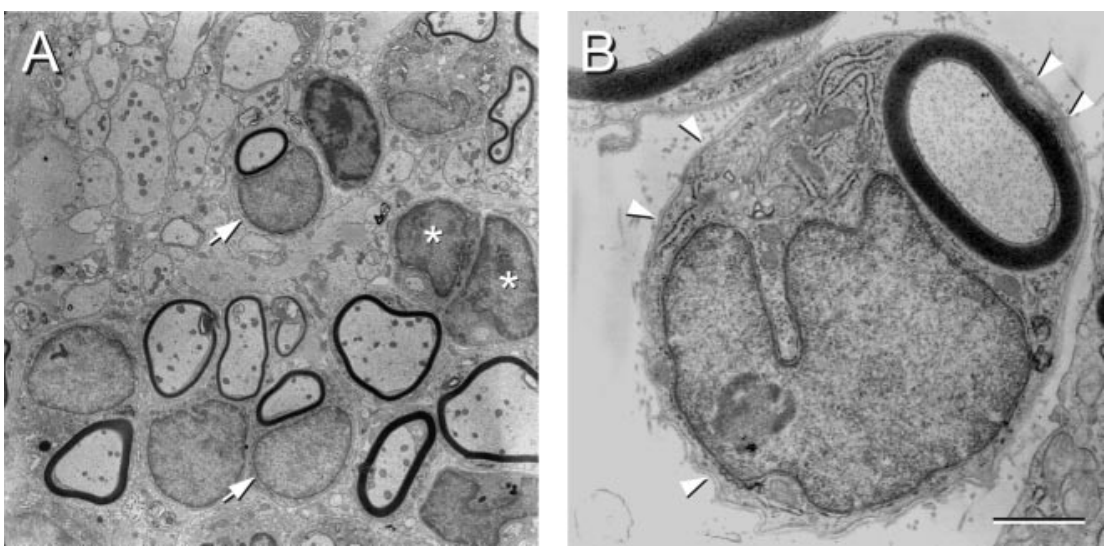

gest that, whereas some axons show stable myelin formation, others appear to be in the process of myelinating. Moreover, a significant number of remyelinated axons have morphological features characteristic of peripheral myelin, which include a large cytoplasmic and nuclear surround.

The low-power field of the dorsal funiculus in Figure $5 A$ from a transplanted rat shows an abundance of GFP fluorescence. A higher-power micrograph (Fig. 5B) shows cellular elements with GFP fluorescence that may be myelinated axons. We parceled tissue into adjacent blocks for frozen and plastic-embedded sections. Figure 5, $C$ and $D$, is from adjacent blocks of the same transplanted animal from a frozen and plastic section, respec- tively. In virtually all transplanted animals in which plasticembedded sections revealed remyelination, adjacent frozen sections showed intense GFP fluorescence. In animals in which no or little remyelination was observed, GFP fluorescence was weak.

Figure $5 E$ is a high-power light micrograph from a frozen section stained with hematoxylin-eosin (H-E) taken within the transplant zone. The arrows point to collapsed axon cylinders surrounded by expanded myelin, which is typical with this histological technique. Note the eosin-stained nuclei (asterisks) associated with some of the myelinated axons. Figure $5 F$ is an unstained frozen section obtained from the same block as in $E$, showing a cluster of cells that are GFP positive. A field of 

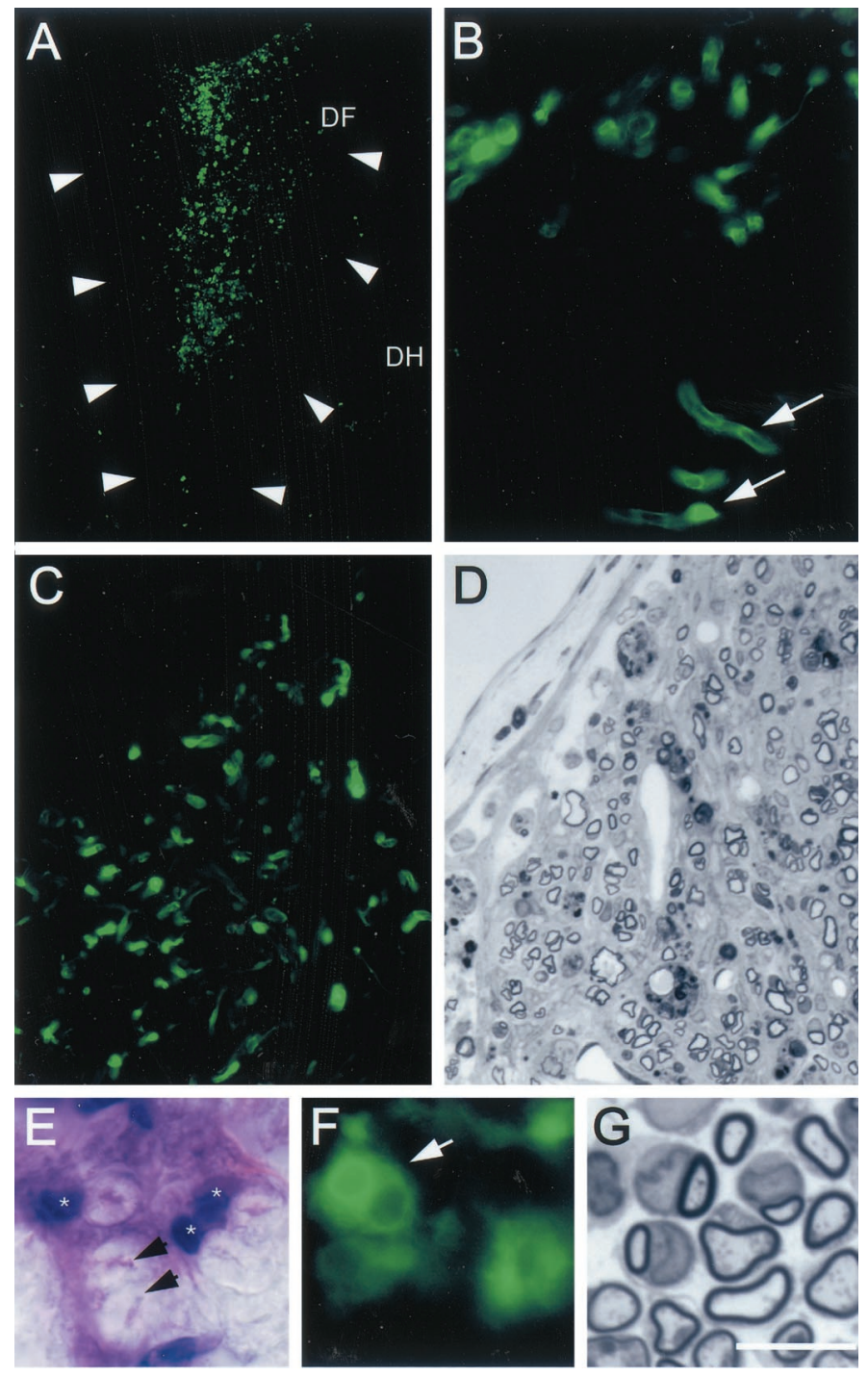

Figure 5. Identification of donor bone marrow cells in vivo. A, Dorsal funiculus $(D F)$ of coronally cut spinal cord from a rat that was injected with bone marrow stromal cells from GFP-expressing mice 3 weeks after transplantation. Arrows indicate the lateral margins of the dorsal funiculus. Numerous GFP-positive cells are observed in the remyelinated region. $D H$, Dorsal horn. $B$, Higher-power image of same field showing profiles reminiscent of myelinated axons. $C$ and $D$ are from frozen and plastic-embedded sections, respectively, from the same animal showing colocalization of GFP fluorescence and more clearly defined myelination in the plastic section. $E$ and $F$ show an H-E-stained frozen section and a fluorescent unstained image with GFP fluorescence at the same high power. Note that, in the frozen $\mathrm{H}-\mathrm{E}$ section, the axon cylinder is collapsed (arrows) and the myelin is "puffy," as is typical with this staining technique. $G$ shows a comparable semithin plastic section from the same animal showing myelinated axons. The myelin is better preserved and the tissue more shrunken form dehydration protocols required for plastic embedding. Scale bar: $A, 250 \mu \mathrm{m} ; B, 50 \mu \mathrm{m} ; C, D, 40 \mu \mathrm{m} ; E, F, 12 \mu \mathrm{m} ; G$, $10 \mu \mathrm{m}$.

remyelinated axons from a plastic-embedded section is shown in Figure $5 G$ for comparison.

Immunostaining was also performed for MBP and $\mathrm{P} 0$ on sections from spinal cords that were transplanted with GFPexpressing stromal cells (Fig. 6). Plastic sections from adjacent blocks of the same spinal cords indicated an abundance of remyelination. Colocalization of both MBP (Fig. 6A-C) and P0 (Fig. $6 D-F)$ with GFP-expressing cells was observed in the transplant
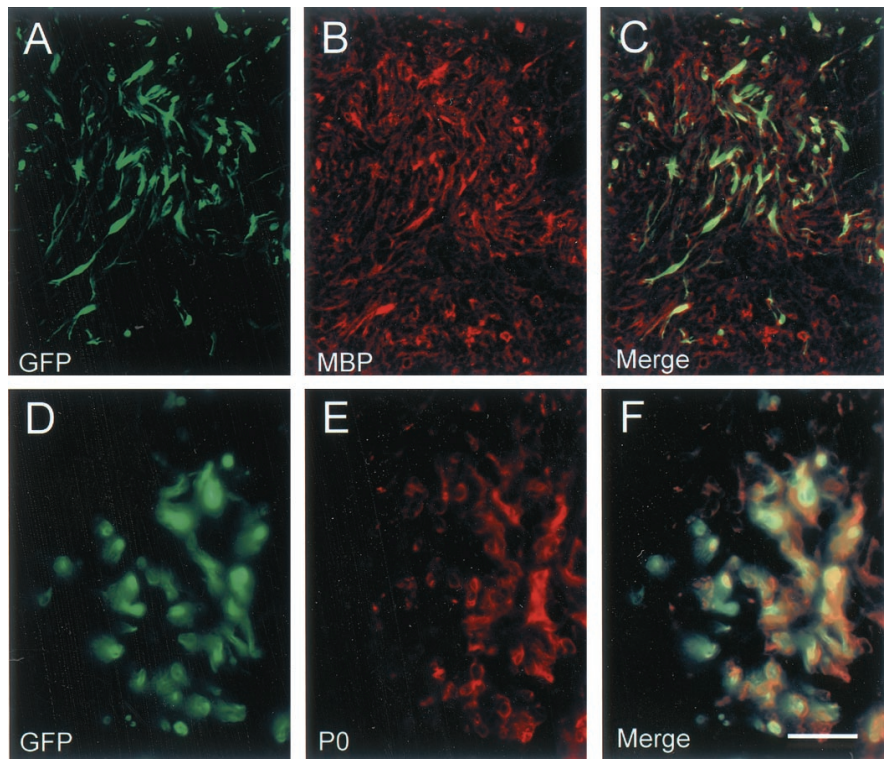

Figure 6. Colocalization of MPB and P0 with transplanted GFPexpressing stromal cells. Cryosections from spinal cord blocks adjacent to plastic-embedded blocks in which remyelination was confirmed showed colocalization of MBP $(A-C)$ and $\mathrm{P} 0(D-F)$ with GFP-expressing elements. Images in $A-C$ were obtained on a confocal microscope, and $D-F$ were obtained on a conventional epifluorescence microscope. Scale bar: $A-C, 70 \mu \mathrm{m} ; D-F, 30 \mu \mathrm{m}$.

zone. Whereas MBP staining was very specific for myelin (both central and peripheral myelin on attached spinal roots), there was considerable MBP staining in the lesion site that was not colocalized with GFP cells. P0 staining was very specific for peripheral roots and cells within the transplant zone. The enhanced MBP staining in the lesion zone may reflect MBP epitope from central myelin debris within the lesion. These results, although not quantitative, indicate the colocalization of transplanted GFPexpressing stromal cells with myelin proteins.

\section{Conduction velocity improves after transplantation of stromal cells}

Electrophysiological studies were performed in vitro to examine the conduction properties of the axons (Fig. 7). Field potential recordings of compound action potentials were recorded with a glass microelectrode from the dorsal columns of control, demyelinated, and bone marrow stromal cell-injected rats, respectively, at sequential longitudinal distances (Fig. $7 A$ ). The early negativity was indicative of the fastest conducting fiber group and is shown at three distances along the conduction trajectory for normal, demyelinated, and stromal cell-transplanted dorsal funiculi (Fig. 7B1-3). The demyelinated axons displayed considerable conduction slowing $(0.89 \pm 0.11 \mathrm{~m} / \mathrm{sec} ; n=12)$ compared with control $(10.76 \pm 1.24 \mathrm{~m} / \mathrm{sec} ; n=12)$. The transplant group had a conduction velocity of $6.03 \pm 1.62 \mathrm{~m} / \mathrm{sec}(n=9)$, which was significantly faster than the demyelinated axons (Fig. 7C). These data indicate that at least a subpopulation of remyelinated axons in the bone marrow stromal cell-injected rats showed increased conduction velocity.

\section{DISCUSSION}

In the present study, we demonstrated that bone marrow stromal cells isolated in culture from the mononuclear layer of bone marrow can remyelinate demyelinated spinal cord axons after direct injection into the lesion. Our results show that (1) ex- 

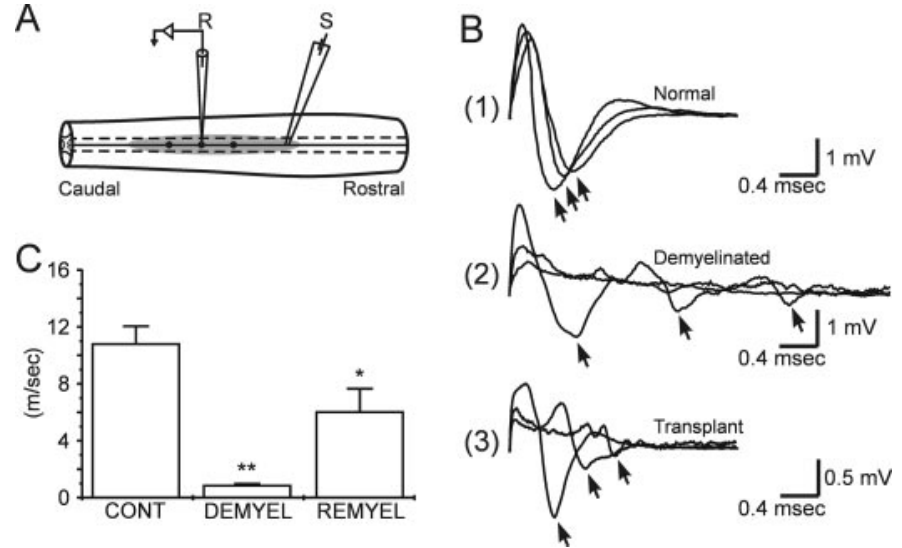

Figure 7. Conduction velocity measurements of the remyelinated axons. $A$, Schematic indicating sites of stimulation $(S)$ and recording $(R)$ within the dorsal funiculus. $B$, Compound action potentials recorded at $1.0 \mathrm{~mm}$ increments longitudinally along the dorsal columns in normal (1), demyelinated (2), and after stromal cell transplantation (3). The arrows in $B$ indicate the peak negativities of three primary negativities. $C$, Histograms of conduction velocity (error bars indicate SEM) of dorsal column axons obtained from normal (CONT), demyelinated (DEMYEL), and remyelinated (REMYEL) axons. At $36^{\circ} \mathrm{C}$, conduction velocity of the early negativity in controls, demyelinated, and bone marrow-delivered groups were $10.76 \pm 1.24 \mathrm{~m} / \mathrm{sec}(n=12), 0.89 \pm 0.11 \mathrm{~m} / \mathrm{sec}(n=12)$, and $6.03 \pm 1.62$ $\mathrm{m} / \mathrm{sec}(n=9)$, respectively. ${ }^{*} p<0.01$, demyelinated versus transplanted; $* * p<0.001$, control versus demyelinated.

panded and isolated bone marrow stromal cells differentiate primarily into myelinating cells when injected into a demyelinated spinal cord lesion, (2) a large number of the myelinated axons have characteristics of peripheral-like myelin with large nuclei and a surrounding basement membrane, and (3) conduction velocity of the remyelinated axons is improved.

\section{Donor cells as the source of myelin-forming cells in vivo}

The lesion model that we used combines focal X-irradiation of the lesion zone to delay endogenous repair in combination with microinjection of ethidium bromide, which kills glia within the lesion zone (Blakemore and Crang, 1985, 1989; Honmou et al., 1996). Although our lesion model is unique in that it represents an aglial zone and most naturally occurring demyelinating disorders are associated with gliosis, this system does provide an important and simple model system to study the interaction of transplanted precursor cells and demyelinated axons in vivo. Virtually no myelination is observed in the lesion zone for 6-8 weeks, at which time, some endogenous myelin repair begins. Our studies were performed at 3 weeks after lesion induction, which is well within the time at which persistent demyelination is observed in this model. However, one cannot completely rule out the possibility that the injected cells recruited or facilitated an endogenous repair mechanism. To address this issue, we used GFPexpressing donor mouse MSCs. The majority of the MSCs cultured from the GFP-expressing mouse strain were GFP positive. It is also important that, in our control experiments, we did not observe remyelination. There are a number of trophic and mitogenic agents in the control media that was injected without cells. This strongly indicates that the medium alone did not enhance or accelerate an endogenous repair mechanism.

MSCs in culture were immunopositive for CD44, collagen I, and fibronectin, which have been shown to be expressed on MSCs (Zohar et al., 1997; Azizi et al., 1998; Conget and Minguell, 1999;
Pittenger et al., 1999). Although we did not triple label the cells, the large proportion of cells immunopositive for these three antibodies suggest colocalization. Our results indicate that, in the spinal cord of rats showing remyelination after injection of donor GFP-expressing MSCs, that GFP-expressing cellular profiles were observed in the remyelination zone and were associated with the myelinated axons. In experiments in which no remyelination was observed, some GFP-like fluorescence was observed, but the intensity was low and no cellular profiles associated with axons were observed. Although we cannot say conclusively that every myelinated axon was the result of the injected donor cells, which is a caveat for all such studies, the intense GFP fluorescence and the cellular morphology of the GFP profiles in areas of remyelination strongly suggest that the donor cells contributed to the remyelination.

\section{Morphology of the remyelinated axons}

The remyelinated axons were densely packed and tended to cluster in the area of cell injection. The lateral margins of the dorsal funiculus remained unmyelinated, suggesting that either cell injection number was relatively low or the cells had limited ability to migrate. However, remyelination was observed along the entire dorsoventral extent of the dorsal funiculus. Interestingly, many of the remyelinated profiles were associated with a large cytoplasmic and nuclear surround, which in turn was enshrouded by a basement membrane. These are hallmark characteristics of peripheral myelin (Berthold, 1978). Neural precursor cells derived from the subventricular zone of postnatal rat (Keirstead et al., 1999) and adult human (Akiyama et al., 2001) brain also can give rise to both central (oligodendrocyte-like) and peripheral (Schwann cell-like) myelin.

There was no obvious neuronal differentiation within the transplantation zone, although marrow cells do have the ability to differentiate into neurons and astrocytes when transplanted into other regions of brain (Azizi et al., 1998; Woodbury et al., 2000). It is not clear whether there are different populations of cells within these progenitor groups or whether regions in the host (transplant recipient) provide signals to direct these cells along different glial or neuronal lineages. It is also unclear as to why these cells develop an almost exclusive myelinating phenotype when transplanted into the demyelinated lesion. One possibility is that the demyelinated white matter in our lesion model is replete with bare axon membrane and phagocytic cells. The ethidium bromide treatment kills virtually all endogenous cells, including astrocytes and oligodendrocytes within the lesion zone, and no endogenous neurons are present in the dorsal funiculus. Axon membrane is known to provide important signals to promote myelin-forming cells to form myelin (Wood and Bunge, 1975; Salzer et al., 1980; Maurel and Salzer, 2000). It is possible that these local axonal signals in the demyelinated lesion direct the lineage of the transplanted MSCs to a myelinating phenotype.

\section{Conduction velocity of the remyelinated axons}

In vitro electrophysiological studies were performed to assess conduction velocity of the remyelinated axons. The results indicate that conduction velocity was significantly increased in the transplantation group compared with the demyelinated group. The velocity was not as fast as controls but was several times greater than the demyelinated axons. However, the increase in conduction velocity as studied over several millimeters of conduction suggest that functional and sequential internodal segments are deposited on at least a subset of the fibers. We limited this study to 3 weeks 
after transplantation. It will be important in the future to determine whether continued maturation of the myelinated axons is accompanied by greater improvement in conduction velocity. These results do indicate that at least a level of functional recovery of conduction is elicited by the MSCs transplantation-induced remyelination.

Oligodendrocytes are the cells that normally myelinate CNS axons, but peripheral myelin-forming cells, such as Schwann cells (Blakemore, 1977) and olfactory ensheathing cells (Franklin et al., 1996; Imaizumi et al., 1998), can myelinate CNS axons in vivo and restore near normal conduction properties (Honmou et al., 1996; Imaizumi et al., 1998). Peripheral myelin-forming cells may have the advantage, if used as a cell therapy in multiple sclerosis (MS) patients, of not having the antigenic properties of oligodendrocytes, which are targets of an immune response in MS patients. Harvesting sufficient numbers of Schwann cells from peripheral nerve biopsy and cell expansion is problematic. However, the development of human clonal neural precursor cells derived from either embryonic or adult CNS (Keirstead et al., 1999; Kukekov et al., 1999; Vescovi et al., 1999; Akiyama et al., 2001) may allow for an abundant source of myelin-forming cells to be used in transplantation studies. Brustle et al. (1999) have demonstrated that human embryonic stem cell-derived glial precursors can be used as a source of myelinating cells in the CNS. Advances in the cell biology of progenitor cells derived from embryonic, fetal, or adult CNS open the prospect of developing cell lines as a potential source of a cell therapy for demyelinating diseases.

Bone marrow stromal cells may offer advantages if developed for cell therapies because the cells are relatively easy to isolate from small aspirates of bone marrow that can be obtained under local anesthesia, and they could provide a vast source of autologous cells for reparative therapies. Thus, MSCs have the potential to provide an efficient and renewable source of cells for autologous transplantation studies for demyelinating diseases. The demonstration that bone marrow stromal cells can form functional myelin when transplanted into demyelinated CNS regions suggests a potentially important interaction between bone marrow cells and CNS white matter repair mechanisms.

\section{REFERENCES}

Akiyama Y, Honmou O, Kato T, Uede T, Hashi K, Kocsis JD (2001) Transplantation of clonal neural precursor cells derived from adult human brain establishes functional peripheral myelin in the rat spinal cord. Exp Neurol 167:27-39.

Akiyama Y, Radtke C, Honmou O, Kocsis JD (2002) Remyelination of the spinal cord axons by intravenous delivery of bone marrow cells. Glia 39:227-234.

Ashton BA, Allen TD, Howlett CR, Eaglesom CC, Hattori A, Owen M (1980) Formation of bone and cartilage by marrow stromal cells in diffusion chambers in vivo. Clin Orthop 151:294-307.

Azizi SA, Stokes D, Augelli BJ, DiGirolamo C, Prockop DJ (1998) Engraftment and migration of human bone marrow stromal cells implanted in the brains of albino rats-similarities to astrocyte grafts. Proc Natl Acad Sci USA 95:3908-3913.

Berthold C-H (1978) Morphology of normal peripheral axons. In: Physiology and pathobiology of axons (Waxman SG, ed), pp 3-64. New York: Raven.

Blakemore WF (1977) Remyelination of CNS axons by Schwann cells transplanted from the sciatic nerve. Nature 266:68-69.

Blakemore WF, Crang AJ (1985) The use of cultured autologous Schwann cells to remyelinate areas of persistent demyelination in the central nervous system. J Neurol Sci 70:207-223.

Blakemore WF, Crang AJ (1989) The relationship between type-1 astrocytes, Schwann cells and oligodendrocytes following transplantation of glial cell cultures into demyelinating lesions in the adult rat spinal cord. J Neurocytol 18:519-528.

Brazelton TR, Rossi FM, Keshet GI, Blau HM (2000) From marrow to brain: expression of neuronal phenotypes in adult mice. Science 290:1775-1779.
Brustle O, Jones KN, Learish RD, Karram K, Choudhary K, Wiestler OD, Duncan ID, McKay RD (1999) Embryonic stem cell-derived glial precursors: a source of myelinating transplants. Science 285:754-756.

Caplan AI (1991) Mesenchymal stem cells. J Orthop Res 9:641-650.

Chen J, Li Y, Wang L, Lu M, Zhang X, Chopp M (2001) Therapeutic benefit of intracerebral transplantation of bone marrow stromal cells after cerebral ischemia in rats. J Neurol Sci 189:49-57.

Chopp M, Zhang XH, Li Y, Wang L, Chen J, Lu D, Lu M, Rosenblum M (2000) Spinal cord injury in rat: treatment with bone marrow stromal cell transplantation. NeuroReport 11:3001-3005.

Conget PA, Minguell JJ (1999) Phenotypical and functional properties of human bone marrow mesenchymal progenitor cells. J Cell Physiol 181:67-73.

Ferrari G, Cusella-De Angelis G, Coletta M, Paolucci E, Stornaiuolo A, Cossu G, Mavilio F (1998) Muscle regeneration by bone marrowderived myogenic progenitors. Science 279:1528-1530.

Franklin RJ, Gilson JM, Franceschini IA, Barnett SC (1996) Schwann cell-like myelination following transplantation of an olfactory bulbensheathing cell line into areas of demyelination in the adult CNS. Glia $17: 217-224$.

Friedenstein AJ (1976) Precursor cells of mechanocytes. Int Rev Cytol 47:327-359.

Gage FH, Coates PW, Palmer TD, Kuhn HG, Fisher LJ, Suhonen JO, Peterson DA, Suhr ST, Ray J (1995) Survival and differentiation of adult neuronal progenitor cells transplanted to the adult brain. Proc Natl Acad Sci USA 92:11879-11883.

Honmou O, Felts PA, Waxman SG, Kocsis JD (1996) Restoration of normal conduction properties in demyelinated spinal cord axons in the adult rat by transplantation of exogenous Schwann cells. J Neurosci 16:3199-3208.

Imaizumi T, Lankford KL, Waxman SG, Greer CA, Kocsis JD (1998) Transplanted olfactory ensheathing cells remyelinate and enhance axonal conduction in the demyelinated dorsal columns of the rat spinal cord. J Neurosci 18:6176-6185.

Johansson CB, Momma S, Clarke DL, Risling M, Lendahl U, Frisen J (1999) Identification of a neural stem cell in the adult mammalian central nervous system. Cell 96:25-34.

Johe KK, Hazel TG, Muller T, Dugich-Djordjevic MM, McKay RD (1996) Single factors direct the differentiation of stem cells from the fetal and adult central nervous system. Genes Dev 10:3129-3140.

Keirstead HS, Ben-Hur T, Rogister B, O'Leary MT, Dubois-Dalcq M, Blakemore WF (1999) Polysialylated neural cell adhesion moleculepositive CNS precursors generate both oligodendrocytes and Schwann cells to remyelinate the CNS after transplantation. J Neurosci 19:7529-7536.

Kukekov VG, Laywell ED, Suslov O, Davies K, Scheffler B, Thomas LB, O'Brien TF, Kusakabe M, Steindler DA (1999) Multipotent stem/ progenitor cells with similar properties arise from two neurogenic regions of adult human brain. Exp Neurol 156:333-344.

Lois C, Alvarez-Buylla A (1993) Proliferating subventricular zone cells in the adult mammalian forebrain can differentiate into neurons and glia. Proc Natl Acad Sci USA 90:2074-2077.

Maurel P, Salzer JL (2000) Axonal regulation of Schwann cell proliferation and survival and the initial events of myelination requires PI 3-kinase activity. J Neurosci 20:4635-4645.

Mezey E, Chandross KJ, Harta G, Maki RA, McKercher SR (2000) Turning blood into brain: cells bearing neuronal antigens generated in vivo from bone marrow. Science 290:1779-1782.

Okabe M, Ikawa M, Kominami K, Nakanishi T, Nishimune Y (1997) "Green mice" as a source of ubiquitous green cells. FEBS Lett 407:313-319.

Owen M (1988) Marrow stromal stem cells. J Cell Sci Suppl 10:63-76.

Pereira RF, Halford KW, O'Hara MD, Leeper DB, Sokolov BP, Pollard MD, Bagasra O, Prockop DJ (1995) Cultured adherent cells from marrow can serve as long-lasting precursor cells for bone, cartilage, and lung in irradiated mice. Proc Natl Acad Sci USA 92:4857-4861.

Phinney DG, Kopen G, Isaacson RL, Prockop DJ (1999) Plastic adherent stromal cells from the bone marrow of commonly used strains of inbred mice: variations in yield, growth, and differentiation. J Cell Biochem 72:570-585.

Pittenger MF, Mackay AM, Beck SC, Jaiswal RK, Douglas R, Mosca JD, Moorman MA, Simonetti DW, Craig S, Marshak DR (1999) Multilineage potential of adult human mesenchymal stem cells. Science 284:143-147.

Prockop DJ (1997) Marrow stromal cells as stem cells for nonhematopoietic tissues. Science 276:71-74.

Reynolds BA, Weiss S (1992) Generation of neurons and astrocytes from isolated cells of the adult mammalian central nervous system. Science 255:1707-1710.

Rickard DJ, Sullivan TA, Shenker BJ, Leboy PS, Kazhdan I (1994) Induction of rapid osteoblast differentiation in rat bone marrow stromal cell cultures by dexamethasone and BMP-2. Dev Biol 161:218-228. 
Salzer JL, Williams AK, Glaser L, Bunge RP (1980) Studies of Schwann cell proliferation. II. Characterization of the stimulation and specificity of the response to a neurite membrane fraction. J Cell Biol 84:753-766.

Sasaki M, Honmou O, Akiyama Y, Uede T, Hashi K, Kocsis JD (2001) Transplantation of an acutely isolated bone marrow fraction repairs demyelinated adult rat spinal cord axons. Glia 35:26-34.

Simmons DJ, Seitz P, Kidder L, Klein GL, Waeltz M, Gundberg CM, Tabuchi C, Yang C, Zhang RW (1991) Partial characterization of rat marrow stromal cells. Calcif Tissue Int 48:326-334.

Vescovi AL, Parati EA, Gritti A, Poulin P, Ferrario M, Wanke E, Frölichsthal-Schoeller P, Cova L, Arcellana-Panlilio M, Colombo A, Galli R (1999) Isolation and cloning of multipotential stem cells from the embryonic human CNS and establishment of transplantable human neural stem cell lines by epigenetic stimulation. Exp Neurol 156:71-83. Wang QR, Wolf NS (1990) Dissecting the hematopoietic microenvironment. VIII. Clonal isolation and identification of cell types in murine CFU-F colonies by limiting dilution. Exp Hematol 18:355-359.

Wood PM, Bunge RP (1975) Evidence that sensory axons are mitogenic for Schwann cells. Nature 256:662-664.

Woodbury D, Schwarz EJ, Prockop DJ, Black IB (2000) Adult rat and human bone marrow stromal cells differentiate into neurons. J Neurosci Res 61:364-370.

Zohar R, Sodek J, McCulloch CA (1997) Characterization of stromal progenitor cells enriched by flow cytometry. Blood 90:3471-3481. 